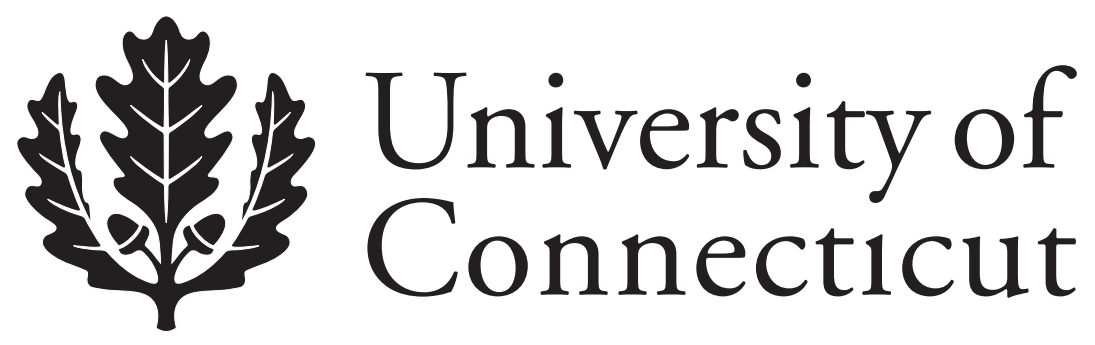

Department of Economics Working Paper Series

\title{
Cross-Country Evidence on Output Growth Volatility: Nonsta- tionary Variance and GARCH Models
}

WenShwo Fang

Feng Chia University

Stephen M. Miller

University of Connecticut and University of Nevada, Las Vegas

ChunShen Lee

Feng Chia University

Working Paper 2007-20

April 2007

341 Mansfield Road, Unit 1063

Storrs, CT 06269-1063

Phone: (860) 486-3022

Fax: (860) 486-4463

http://www.econ.uconn.edu/

This working paper is indexed on RePEc, http://repec.org/ 


\begin{abstract}
This paper revisits the issue of conditional volatility in real GDP growth rates for Canada, Japan, the United Kingdom, and the United States. Previous studies find high persistence in the volatility. This paper shows that this finding largely reflects a nonstationary variance. Output growth in the four countries became noticeably less volatile over the past few decades. In this paper, we employ the modified ICSS algorithm to detect structural change in the unconditional variance of output growth. One structural break exists in each of the four countries. We then use generalized autoregressive conditional heteroskedasticity (GARCH) specifications modeling output growth and its volatility with and without the break in volatility. The evidence shows that the time-varying variance falls sharply in Canada, Japan, and the U.K. and disappears in the U.S., excess kurtosis vanishes in Canada, Japan, and the U.S. and drops substantially in the U.K., once we incorporate the break in the variance equation of output for the four countries. That is, the integrated GARCH (IGARCH) effect proves spurious and the GARCH model demonstrates misspecification, if researchers neglect a nonstationary unconditional variance.
\end{abstract}

Journal of Economic Literature Classification: C32; E32; O40

Keywords: Nonstationary variance, the Great Moderation, real GDP growth and volatility, modified ICSS algorithm, IGARCH effect 


\section{Introduction}

The Great Moderation captured the attention of macroeconomists, especially since the decline in volatility of real GDP growth occurs in numerous developed countries. Several important issues emanate from this phenomenon. First, what caused the decline in volatility? Analysts offer several hypotheses, including better macroeconomic policies, structural change, or good luck. ${ }^{1}$ Second, how does one model the decline in volatility? Researchers frequently employ some form of a generalized autoregressive conditional heteroskedasticity $(\mathrm{GARCH})$ modeling strategy to capture the movement in volatility under the assumption of a stable variance process. Third, does the reduction in output growth volatility feedback and raise the real GDP growth rate? The existing empirical evidence on this third question provides mixed evidence.

Our paper focuses on the latter two questions, putting aside the issue of what precipitated the decline in macroeconomic volatility. First, we argue that the extent methods of modeling the time-series properties of the volatility of the real GDP growth rate contain misspecifications associated with structural shifts. We correct such misspecifications by introducing a one-time structural shift in the volatility process. Second, given our improved specification of output growth volatility, we reconsider the effect of the real GDP growth rate volatility on the real GDP growth rate. In addressing both questions, we examine four countries - Canada, Japan, the United Kingdom, and the United States.

\footnotetext{
${ }^{1}$ Good policies refer to better management of the economy by monetary policy makers. Structural change refers to better inventory management. Good luck refers to the reduction in economic shocks (e.g., oil price shocks). Bernanke (2004) uses a lower-bound frontier on inflation and output volatilities to organize his thinking. Inefficient monetary policy or inventory management leaves the economy above the frontier, whereas changes in the volatility of random shocks will shift the lower-bound frontier. Stock and Watson (2003) attribute the Great Moderation to good luck, implying that the frontier shifted toward the origin. Bernanke (2004) argues that a substantial portion of the Great Moderation reflects better monetary policy, implying a movement toward the frontier. The distinction proves important, because if Stock and Watson (2003) prove correct, then good luck can turn into bad luck and the frontier can shift back to a more unfavorable trade-off. If Bernanke (2004) proves correct, then maintaining good policy can continue the benefits of the Great Moderation.
} 
Kim and Nelson (1999), McConnell and Perez-Quiros (2000), and Blanchard and Simon (2001), among others, document a structural change in the volatility of U.S. GDP growth, finding a rather dramatic reduction in GDP volatility since the early 1980s. Mills and Wang (2003) and Summers (2005) find a structural break in the volatility of the output growth rate for the G7 countries, although the break occurs at different times.

Most research on the various aspects of output volatility, such as asymmetry or its effect on the growth rate, assumes a stable GARCH process governing conditional growth volatility. The neglect of structural breaks in the unconditional variance of output leads to higher persistence in the conditional volatility. For example, in Hamori (2000), the GARCH persistence of volatility equals 0.972 for Japan, 0.857 for the U.K., and 0.987 for the U.S. In Ho and Tsui (2003), the exponential GARCH (EGARCH) persistence of volatility equals 0.848 for Canada, 0.834 for the U.K., and 0.916 for the U.S. All the persistence measures fall close to one.

Economic growth involves long-run phenomena. For longer sample periods, structural changes in volatility will occur with a higher probability. Hamilton and Susmel (1994) and Kim et al. (1998) suggest that the long-run variance dynamics may include regime shifts, but within a regime it may follow a GARCH process. Kim and Nelson (1999), Mills and Wang (2003), Bhar and Hamori (2003), and Summers (2005) apply this approach of Markov switching heteroskedasticity with two states to examine the volatility in the growth rate of real GDP. The GARCH modeling approach provides an alternative to deal with this issue, but relaxing the implicit assumption of a constant unconditional variance.

Diebold (1986) raises the concern that structural changes may confound persistence estimation in GARCH models. He notes that Engle and Bollerslev's (1986) integrated GARCH (IGARCH) may result from instability of the constant term of the conditional variance, that is, 
nonstationarity of the unconditional variance. Neglecting such changes can generate spuriously measured persistence with the sum of the estimated autoregressive parameters of the conditional variance heavily biased towards one. Lamoureux and Lastrapes (1990) explore Diebold's conjecture and provide confirming evidence that not accounting for discrete shifts in unconditional variance, the misspecification of the GARCH model, can bias upward GARCH estimates of persistence in variance. Including dummy variables to account for such shifts diminishes the degree of GARCH persistence. More recently, Mikosch and Stărică (2004) argue theoretically that the IGARCH model makes sense when non-stationary data reflect changes in the unconditional variance. Hillebrand (2005) shows that in the presence of neglected parameter change-points, even a single deterministic change-point, GARCH inappropriately measures volatility persistence.

The evidence of declining output volatility combined with finding an IGARCH in conditional volatility motivates us to revisit conditional volatility in real GDP growth rates for Canada, Japan, the U.K., and the U.S. We first employ the iterated cumulative sum of squares (ICSS) algorithm, newly modified by Sansó, Arragó, and Carrion (2004) to detect sudden changes in the variance of output growth. Then we apply GARCH specifications, modeling output growth and its volatility with and without breaks in volatility. The evidence shows that the time-varying variance falls sharply or even disappears entirely, once we incorporate the breaks in the variance equation of output for the four countries. That is, the IGARCH effect proves spurious due to nonstationary variance.

The rest of the paper unfolds as follows. Section 2 discusses the data and structural changes in output volatility. Section 3 presents the methodology and the empirical results. Section 4 considers additional evidence on the relationship between the output growth rate and its volatility. Finally, Section 5 concludes. 


\section{Data and structural change in variance}

Output growth rates $\left(y_{t}\right)$ equal the percentage change in the logarithm of seasonally adjusted quarterly real GDP $\left(Y_{t}\right)$ in Canada, Japan, the U.K., and the U.S., that come from the IMF International Financial Statistics over the period 1957:1 to 2006:3. The identification of change points will occur endogenously in the data generating process. We employ the modified ICSS algorithm, proposed originally by Inclán and Tiao (1994) and adjusted recently by Sansó, Arragó, and Carrion (2004) to detect structural changes in the variance. The analysis assumes that the time series of output growth displays a stationary variance over an initial period, and then a sudden change in variance occurs. The variance then exhibits stationarity again for a time, until the next sudden change. The process repeats through time, yielding a time series of observations with an unknown number of changes in the variance. ${ }^{2}$

In Inclán and Tiao (1994), the ICSS tests for changes in the unconditional variance of a stochastic process, assuming that the disturbances prove independent with Gaussian distributions. Let $\left\{\varepsilon_{t}\right\}$ denote a series of independent observations from a normal distribution with mean zero. When $\mathrm{N}$ variance changes occur in $\mathrm{T}$ observations, $1<k_{1}<k_{2}<\ldots<k_{N}<\mathrm{T}$ equal the set of change points. Let $C_{k}$ equal the cumulative sum of the squared observations from the start of the series to the $\mathrm{k}^{\text {th }}$ point in time (i.e., $\left.C_{k}=\sum_{t=1}^{k} \varepsilon_{t}^{2}, \mathrm{k}=1, \ldots, \mathrm{T}\right)$. Then, define $D_{k}$ as : $D_{k}=\left(C_{k} / C_{T}\right)-k / T, k=1, \ldots, T$ with $D_{0}=D_{T}=0$. If no changes in variance occur over the sample period, the $D_{k}$ statistic oscillates around zero. If one or more sudden variance changes

\footnotetext{
2 Aggarwal, Inclán, and Leal (1999) apply Inclán and Tiao’s (1994) ICSS algorithm to identify the points of sudden changes in the variance of returns in ten emerging stock markets, in addition to Hong Kong, Singapore, Germany, Japan, the U.K., and the U.S. More recently, Rapach and Strauss (2007) employ Sansó, Arragó, and Carrion's (2004) modified ICSS to detect structural breaks in the unconditional variance of eight U.S. dollar exchange rate return series.
} 
exist in the series, then the $D_{k}$ values drift either up or down and away from zero. Critical values based on the distribution on $D_{k}$ under the null hypothesis of homogeneous variance provide upper and lower boundaries to detect a significant change in variance with a known level of probability. When the maximum of the absolute value of $D_{k}$ exceeds the critical value, we reject the null hypothesis of no changes. Let $k^{*}$ equal the value of $\mathrm{k}$ for which $\max _{\mathrm{k}}\left|D_{k}\right|$ occurs. If $\max _{\mathrm{k}}(T / 2)^{0.5}\left|D_{k}\right|$ exceeds the predetermined boundary, then k provides an estimate of the change point. The factor $(T / 2)^{0.5}$ standardizes the distribution. Under the null, $D_{k}$ asymptotically behaves as a Brownian bridge.

Economic and financial time series, however, usually show distributions with fat tails (leptokurtic) and persistence in the conditional variance. Sansó, Arragó, and Carrion (2004) find size distortions for the ICSS test when the series are leptokurtic as well as conditionally heteroskedastic, which produce spurious changes in the unconditional variance. To overcome these problems, they adjust the test by explicitly considering the fourth moment properties of the disturbances and the conditional heteroskedasticity, using a nonparametric adjustment based on the Bartlett kernel. The modified statistic equals $\max _{\mathrm{k}} T^{-0.5}\left|G_{k}\right|$, where $G_{k}=\left[\hat{\gamma}_{0}+2 \sum_{l=1}^{m}\left[1-l(m+1)^{-1}\right] \hat{\gamma}_{l}\right]^{-0.5}\left[C_{k}-(k / T) C_{T}\right], \hat{\gamma}_{l}=T^{-1} \sum_{t=l+1}^{T}\left(\varepsilon_{t}^{2}-C_{T} / T\right)\left(\varepsilon_{t-1}^{2}-C_{T} / T\right)$, and the procedure in Newey and West (1994) generates the lag truncation parameter m. Under general conditions, the modified ICSS statistic $\max _{\mathrm{k}} T^{-0.5}\left|G_{k}\right|$ exhibits the same asymptotic distribution as that of $\max _{\mathrm{k}}(T / 2)^{0.5}\left|D_{k}\right|$, and simulations generate finite-sample critical values.

To examine multiple change points, the modified ICSS algorithm successively evaluates 
$G_{k}$ at different parts of the series, dividing consecutively after finding a possible change point. ${ }^{3}$ In our application, the procedure identifies a single structural break in the unconditional variance of growth rates for each of the four countries. Thus, change in the GARCH process governs volatility. Different countries experience different break dates, that is, 1991:2 in Canada, 1975:1 in Japan, 1991:4 in the U.K., and 1982:1 in the U.S. Blanchard and Simon (2001) also analyze the large decline in U.S. output volatility starting in 1982:1, but two years earlier than that of 1984:1 in McConnell and Perez-Quiros (2000).

On the one hand, Mills and Wang (2003) fit Hamilton's Markov chain model to post-war quarterly output growth that allows for a one-time structural break and find the break around the late 1970s in Canada, 1976 in Japan, 1993 in the U.K., and 1984 in the U.S. Summers (2005), on the other hand, uses the probability that GDP volatility in any particular quarter is high or low and reports the date of the switch from high to low volatility at 1988:1 in Canada, 1975:2 in Japan, 1982:2 in the U.K., and 1984:4 in the U.S. Different approaches may lead to different findings of the break date in a country. Generally, the evidence indicates that the U.S. break date occurs some time in the early to mid-1980s and Japan experiences a decline in the mid 1970s. But for Canada and the U.K., the timing of the decline seems controversial. For Canada, our break date, 1991:2, comes close to the 1988:1 break point in Summers (2005), but relatively far from the late 1970s break point in Mills and Wang (2003). For the U.K., however, our break date, 1991:4, comes closer to the 1993 break point in Mills and Wang (2003) than to the 1982:2 break point in Summers (2005).

Figure 1 plots the series of real GDP growth rate and marks the break identified by the

\footnotetext{
${ }^{3}$ We implement the modified ICSS algorithm using the GAUSS procedures available from Andreu Sansó's web page at http://www.uib.es/depart/deaweb/personal/profesores/personalpages/andreusanso/we.
} 
modified ICSS algorithm, as well as three-standard-deviation bands for each of the regimes. We further conduct structural stability tests for the unconditional mean and variance of the growth rate by splitting the sample into two sub-periods according to the break date in each country. For the unconditional mean, a Wald statistic tests for the equality of means for two different samples, while a variance-ratio statistic tests for the equality of the unconditional variances.

Table 1 reports descriptive statistics for the data and the results of the structural stability tests. In Panel A, Japan shows the highest mean growth rate of 1.0941 percent for the full 50-year sample. The U.K. has the lowest of 0.6107. Canada and the U.S. fall between at 0.8589 and 0.8103 , respectively. Moreover, Japan also displays the highest output volatility, represented by the standard deviation of 1.7906 , and Canada exhibits the lowest of 0.8854 . Skewness statistics support symmetric distributions only for Canada. Kurtosis statistics exhibit leptokurticity with fat tails for all countries except Canada. Consequently, Jarque-Bera tests reject normality for Japan, the U.K., and the U.S., but cannot reject normal distributions in Canada. The ADF unit-root test implies that the growth rate exhibits stationarity for each of the four samples.

Panel B splits the full sample into two sub-samples at the break date. For Canada, the U.K., and the U.S., the mean growth rate in each sub-sample nearly equals the growth rate average for the full sample. The Wald statistics, distributed as $\chi^{2}(1)$, that test for structural change in the mean between the samples cannot reject the null hypothesis of equality of means. Japan experiences a significant drop in the mean growth from 2.2866 in the pre-1975 sample period to 0.4977 in the post-1975 period. A clear decline in the standard deviation of the growth rate occurs for all the four countries, however. The p-values for the variance-ratio F-test significantly reject the null of variance equality between the samples. The decline equals 53 percent in Canada, 42 percent in Japan, 73 percent in the U.K., and 46 percent in the U.S. The large decline in the U.K. appears in 
Figure 1 as compared to other three countries. As noted in the introduction, economists call the substantial drop in the variance of output growth in the period after the break as the Great Moderation. Most research focuses on the causes of the Great Moderation such as good policies, structural change, good luck, or output composition shifts, as discussed in McConnell and Perez-Quiros (2000), Blanchard and Simon (2001), Stock and Watson (2003), Ahmed et al. (2004), Bernanke (2004), Summers (2005), and Eggers and Ioannides (2006). This paper examines the effect of the Great Moderation on the time-series specification of output growth volatility in GARCH models (i.e., Section 3) as well as the effect, if any, of our output growth volatility measure on output growth (i.e., Section 4).

\section{Time-Series Specification of Output Growth Volatility}

We first construct ARMA models for the growth rate series. Based on the Schwarz Bayesian Criterion (SBC), the $\mathrm{AR}(1)$ process proves adequate to capture growth dynamics and produces white-noise residuals for Canada, AR(4) for Japan, AR(3) for the U.K., and AR(2) for the U.S. The general mean growth rate equation equals the following:

$$
y_{t}=a_{0}+\sum_{i=1}^{4} a_{i} y_{t-i}+\varepsilon_{t}
$$

where the growth rate $y_{t} \equiv 100 \times\left(\ln Y_{t}-\ln Y_{t-1}\right), \ln Y_{t}$ equals the natural logarithm of real GDP, $\varepsilon_{t}$ equals the white-noise random error.

The GARCH(1,1) specification proves adequate to represent most financial and economic time series. Hamori (2000), Henry and Olekalns (2002), and Ho and Tsui (2003) apply this process to parameterize the time-varying conditional variance of output growth for the four countries studied. To consider the effect of the Great Moderation on the variance of output in the GARCH specification, we include a dummy variable in the conditional variance equation, which equals unity from the break date forward, zero otherwise, for our four sample countries as follows:. 


$$
\sigma_{t}^{2}=\alpha_{0}+\alpha_{1} \varepsilon_{t-1}^{2}+\beta_{1} \sigma_{t-1}^{2}+\gamma \text { Dummy }_{j}, j=C, J, U K, \text { and } U S,
$$

where Dummy $_{C}=1$ for $t \geq 1991: 2,0$ otherwise, for Canada, Dummy $=1$ for $t \geq 1975: 1,0$ otherwise, for Japan, Dummy ${ }_{U K}=1$ for $t \geq 1991: 4,0$ otherwise, for the U.K., Dummy ${ }_{U S}=1$ for $t \geq 1982: 1,0$ otherwise, for the U.S., and $\sigma_{t}^{2}$ equals the conditional variance of the growth rate, given information available at time t-1. The conditions that $\alpha_{i} \geq 0, \beta_{i} \geq 0$, and $\alpha_{1}+\beta_{1}<1$ ensure positive and stable conditional variances of $\varepsilon_{t}$. The sum, $\alpha_{1}+\beta_{1}$, measures the persistence of shocks to the conditional variances. Evidence of an IGARCH, or, in general, evidence of high persistence proves analogous to a unit root in the mean of a stochastic process. This persistence may result from occasional level shifts in volatility. The dummy variable accommodates the extraordinary change. If $\beta_{1}$ equals zero, the process reduces to an $\mathrm{ARCH}(1)$. When $\alpha_{1}$ and $\beta_{1}$ both equal zero, the variance equals a constant. We estimate each of the models employing Bollerslev and Wooldridge's (1992) quasi-maximum likelihood estimation (QMLE) technique, assuming normally distributed errors and using the Berndt et al. (1974) (BHHH) algorithm.

We first estimate the $\operatorname{GARCH}(1,1)$ models without structural breaks in the variance equation. That is, we do not know whether a structural break exists as a counterfactual experiment. Table 2 reports the estimation results with standard errors in parentheses, p-values in brackets, and statistics for the standardized residuals. In the mean equation, most AR estimates verify significance at the 5-percent level, lending support to the autoregressive specification. Each estimate in the variance equation exceeds zero. The volatility persistence measures, 0.9912 in Canada, 0.9739 in Japan, 0.9693 in the U.K., and 0.9842 in the U.S., all nearly match those reported in Hamori (2000) and Ho and Tsui (2003) and prove high. The likelihood ratio (LR) tests for $\alpha_{1}+\beta_{1}=1$ in the GARCH process do not reject the null hypothesis of an IGARCH effect at the 
5-percent level for all specifications. The model contained in equations (1) and (2) assumes that positive and negative shocks generate the same effect on volatility for each country. We employ Engle and Ng's (1993) diagnostic test to detect asymmetry in variance of the growth rates. The null hypothesis assumes no asymmetric effect in volatility. The joint test statistics (Engle-Ng) all indicate insignificance at the 5-percent level, supporting the symmetric GARCH models specified for the sample countries. The fitted models adequately capture the time-series properties of the data in that the Ljung-Box Q-statistics for standardized residuals ( $L B Q$ ) and standardized squared residuals $\left(L B Q^{2}\right)$, up to 6 lags, do not detect remaining autocorrelation and conditional heteroskedasticity. The standardized residuals exhibit symmetric distributions in Canada and the U.S., but not in Japan and the U.K., and significant excess kurtosis exists in all countries. Thus, they do not exhibit the characteristics of a normal distribution.

The empirical results raise two issues. First, the Great Moderation in the volatility of GDP growth identified by the modified ICSS algorithm (i.e., one-time structural break) suggests that the volatility persistence identified in the GARCH models may prove spurious, since researchers do not incorporate structural change in the variance. Lastrapes (1989) shows that changes in the unconditional variance should receive consideration when specifying ARCH models. In his study, for instance, the persistence of volatility in exchange rates decreases after incorporating three U.S. monetary policy regime shifts between 1976 and 1986, diminishing the likelihood of integration-in-variance. Tzavalis and Wickens (1995) find strong evidence of a high degree of persistence in the volatility of the term premium of bonds. Once they allow for the monetary regime shift between 1979 and 1982, however, the high persistence in the GARCH(1,1)-M model disappears.

Second, the significant statistical property of excess kurtosis provides a cautionary note. 
Kurtosis for the standardized residuals (i.e., $\varepsilon_{t} / \sigma_{t}$ ) should fall below that for the unconditional standard deviation. According to the distributional assumptions in the GARCH specification, the standardized residuals should reflect a normal distribution, if the GARCH model totally captures the leptokurtic unconditional distribution. The sample kurtosis in Table 2 for the standardized residuals indicates that GARCH incorporates some, but not all, of the leptokurtosis for the output growth rate in Japan, the U.K., and the U.S., and none in Canada. Blanchard and Simon (2001) note that the distribution of output growth exhibits excess kurtosis (or skewness), if large and infrequent shocks occur. This suggests that the evidence of excess kurtosis may also reflect the Great Moderation. Generally, empirical studies report the first- and second-order serial correlation in the standardized residuals of the GARCH estimation based on Ljung-Box diagnostic statistics, but often lack skewness, excess kurtosis, and normality tests. We argue that the higher moments of the standardized residuals provide important diagnostic information regarding accurate model specification and the true data generating process, particularly, when structural change in variance may occur.

Thus, we expect to resolve the two puzzles by modeling the non-stationarity variance arising from the Great Moderation. First, the high persistence of output volatility decreases after accounting for the Great Moderation, diminishing the likelihood of biasing the sum of the estimated autoregressive parameters toward one. Second, leptokurtosis in the unconditional distribution of output growth falls substantially or vanishes after adjustment for GARCH with the structural break.

Japan requires special attention because structural change also occurs in the mean as well as the variance of the growth rates at the break date 1975:1 in Table 1, the only country that faces this complication among the four countries studied. An examination of the data suggests an outlier 
in the growth rate series that equals -6.6422 in $1974: 1$, as compared to the mean value of 1.0941 with a standard deviation 1.7906 for the series. Thus, we introduce an impulse dummy variable in the mean equation, defined as Idummy $_{J}=1$ for $\mathrm{t}=1974: 1$, zero otherwise, representing the outlier. To capture the mean shift, the same dummy variable, defined above as Dummy $_{J}=1$ for $t \geq 1975: 1$, zero otherwise, also enters into the mean equation. That is, we include a one-time impulse dummy variable and the intercept-shift dummy variable in equation (1) as well as the same intercept-shift dummy variable in equation (2) for Japan.

When we include these two dummy variables in the mean equation, but exclude the shift dummy variable from the variance equation, the GARCH model estimates nearly match those in Table 2 for Japan. In particular, the high volatility persistence $(=0.9791)$ remains, meaning that the mean shift does not explain the IGARCH effect. See Table A1 in Appendix A. Sensier and van Dijk (2004, p. 835) conjecture that changes in the mean equation may explain changes in the unconditional volatility. Our findings do not support their conjecture when incorporating the one-time impulse or intercept-shift dummy variables individually or in tandem. Intuitively, mean shifts capture changes in the intercept, and not the volatility. In other words, the one-time impulse and intercept-shift dummy variables affect the distributional behavior of the residuals, but not the IGARCH process, which reflects the nonstationary variance. ${ }^{4}$

\footnotetext{
${ }^{4}$ Engle and $\mathrm{Ng}$ (1993) asymmetric test exhibits some sensitivity to the GARCH model specification. In Table 2, Japan and the other three countries all pass the Engle-Ng test. In Table A1, however, only the GARCH model with the intercept-shift dummy passes the test for Japan. The other two Japanese specifications suggest that positive and negative shocks may affect the volatility differently. As a result, Table A2 reports the EGARCH estimates for Japan. The results again show ambiguous evidence in that the asymmetric parameter, $\gamma$, proves insignificant, suggesting no need for such a model, although the residuals now pass the Engle-Ng test. Hamori (2000), Ho and Tsui (2003), and Fountas et al. (2004) also report an insignificant $\gamma$. Nonetheless, high persistence, measured by $\beta$, emerges in each of the three models. The LR test cannot reject the null hypothesis of $\beta=1$. In sum, either symmetric or asymmetric GARCH modeling specifications (in Tables A1 and A2) results in an IGARCH estimation under the Great Moderation. We proceed by focusing on the effect of nonstationary variance on conditional volatility, using a symmetric GARCH specification.
} 
Table 3 reports the estimates with the break, showing that the structural dummy proves highly significant in the variance equation in all four cases and also significant in the mean equation in Japan, where $d_{1}$ and $d_{2}$ are coefficients of the impulse dummy variable and the intercept-shift dummy variable, respectively. The improvement of the value of the maximum log-likelihood (see Tables 2 and 3) indicates that including the dummy variable in the GARCH equation provides a better specification. The Ljung-Box Q-statistics of the standardized residuals and the squared standardized residuals show no evidence of autocorrelation and heteroskedasticity, providing support for these specifications. The Engle-Ng diagnostic statistics suggest no need of an asymmetric model, except for Japan at the 10-percent level (see footnote 4). The coefficients of skewness and excess kurtosis prove insignificant at the 5-percent level for Canada, Japan, and the U.S. And, thus, the standardized residuals conform to a normal distribution in the three countries. For the U.K., excess kurtosis remains, but drops sharply as compared with that in Tables 1 and 2. Blanchard and Simon (2001) find significant skewness and excess kurtosis of U.S. real GDP growth only around the early 1980 s recession. These results match our findings. In sum, by incorporating a one-time structural shift in the GARCH variance equations, we observe insignificant skewness and excess kurtosis in three of four countries studied.

Two important consequences emerge by allowing for a structural change in the conditional variance. First, a large decline occurs in the estimated degree of persistence in the conditional variance. Each estimate in the variance equation in Table 3 falls below the similar model without the dummy variable in Table 2. The significant LR statistic at least at the 10-percent level in Table 3 proves no IGARCH effect in each of the four countries. In addition, the estimates of $\alpha_{1}$ and $\beta_{1}$ not only fall in size but also become insignificant in the specification that includes the dummy variable in the U.S., indicating no ARCH or no GARCH effects. That is, the dummy variable 
replaces the GARCH effect. Moreover, the GARCH(1,1) model reduces to $\mathrm{ARCH}(1)$ in Canada, Japan, and the U.K. Second, the interaction between the dummy variable and the excess kurtosis in Canada, Japan, and the U.S., which previously proved significant in Table 2, now proves insignificant. In the U.K., the kurtosis drops by a large amount from 3.2265 in Table 2 to 1.0127 in Table 3. These results suggest that the statistical evidence for time-varying variance and for excess kurtosis in the growth rate may reflect a shift in the unconditional variance caused by the Great Moderation. Figure 2 plots the conditional variances with and without dummy variables for the four models, respectively. The solid line includes the dummy variable while the dashed line excludes the dummy variable. One common characteristic appears in the diagrams for the four countries -- a clear shift in the variance. The high volatility appears in the period before the break date in each of the four countries.

\section{Output Growth Volatility and Output Growth}

The prior section considers the appropriate time-series specification of the volatility of the growth rate of real GDP. A number of authors examine the issue of how this volatility affects the growth rate of GDP. That is, does decreased real GDP growth rate volatility cause a higher or lower real GDP growth rate? For example, applying a GARCH in mean (GARCH-M) model and using post-war real quarterly GDP data, Henry and Olekalns (2002) discover a significant GARCH effect and a negative link between volatility and growth for the U.S. ${ }^{5}$ This section pursues this question with our more appropriate time-series specification of the real GDP growth rate volatility, employing a GARCH-M(1,1)-M model to examine the effect of output volatility on the output growth rate for our four sample countries.

\footnotetext{
5 Poterba and Summers (1986) note that the degree of persistence in variance of a variable importantly affects the relationship between the variable and its volatility, for example, stock returns and their volatility.
} 
Alternative theoretical models give mixed results -- negative, positive, or independent relationships between output growth volatility and output growth. For example, the misperceptions theory, proposed originally by Friedman (1968), Phelps (1968), and Lucas (1972), argues that output fluctuates around its natural rate, reflecting price misperceptions due to monetary shocks. The long-run growth rate of potential output, however, reflects technology and other real factors. The standard dichotomy in macroeconomics implies no relationship between output volatility and its growth rate. Martin and Rogers $(1997,2000)$ argue that learning-by-doing generates growth whereby production complements productivity-improving activities and stabilization policy can positively affect human capital accumulation and growth. One natural conclusion, therefore, implies a negative relationship between output volatility and growth. In contrast, Black (1987) argues that high output volatility and high growth coexist. According to Blackburn (1999), a relative increase in the volatility of shocks increases the pace of knowledge accumulation and, hence, growth, implying a positive relation between output volatility and growth.

Table 4 reports the GARCH(1,1)-M estimation results, where we include the one-time structural break in the variance process. The presence of the standard deviation (i.e., the square root of the variance) in the mean equation of the growth rate makes equations (1) and (2) a GARCH-M model (Engle et al., 1987). The coefficient of the conditional standard deviation $(\lambda)$ possesses no statistical significance in Japan, the U.K., and the U.S., but significance at the 5-percent level in Canada. All other estimates and diagnostic statistics mirror those in the models without this mean effect. The insignificant estimate of $\lambda$ in the mean equation implies no relationship between output volatility and its growth in Japan, the U.K., and the U.S. This result conforms to the misperceptions hypothesis and the previous empirical findings, using GARCH-M 
models, of Grier and Perry (2000) and Fountas and Karanasos (2006) for the U.S. and Speight (1999) for the U.K. This finding, however, proves inconsistent with the discovery of a positive relationship by Caporale and McKiernan $(1996,1998)$ for the U.K. and the U.S., and by Fountas and Karanasos (2006) for Japan, as well as the discovery of a negative relationship by Henry and Olekaln (2002) for the U.S. The significant and positive estimate of $\lambda$ supports the Black (1987) hypothesis for Canada.

Different empirical findings between Henry and Olekaln (2002) and this paper may come from several sources. First, although we use almost the same sample size, our quarterly data spanning 1957:1 to 2006:3 contain much more recent data than the sample in Henry and Olekaln (2002) from 1947:1 to $1998: 4$. The more recent data on growth rate volatility exhibit substantial declines. Reduced volatility may neutralize the negative effect of volatility on the growth rate. Second, Henry and Olekaln (2002) use an asymmetric threshold GARCH (TGARCH) of Glosten et al. (1993). In our Table 4, the Engle-Ng (1993) diagnostic test shows no asymmetric effect under a symmetric GARCH specification, suggesting no need for an asymmetric model. This conclusion also receives support from Hamori (2000), who shows that the GARCH version provides the best statistical fit compared to EGARCH and TGARCH and that the volatility process proves symmetric for the U.S., the U.K., and Japan. Third, and most importantly, Henry and Olekaln (2002) assume implicitly that a stable GARCH process governs conditional growth volatility. The neglect of the structural break in the unconditional variance identified by the modified ICSS algorithm (also documented in other studies using other methods) proves misspecification of the conditional variance. That may lead to significant GARCH and, thus, GARCH-M effects.

For the differences with other studies, Caporale and McKiernan (1998) and Fountas and Karanasos (2006) use annual real GNP or IP (industrial production) data. Caporale and McKiernan 
(1996), Speight (1999), and Grier and Perry (2000) use monthly IP to examine the effect of output volatility on its growth. The data frequency may provide another avenue for differences in findings. Existing research efforts, however, do not limit the phenomenon of the Great Moderation to quarterly output only. For example, Sensier and van Dijk (2004) find approximately 80 percent of 214 monthly U.S. macroeconomic time series, including IP, experience a break in the unconditional volatility over the period 1959-1999, with most breaks occurring after 1980 . The finding of GARCH-M effects, significant or not, may prove spurious, since these researches fail to account for the structural change in the variance. Our GARCH-M estimation results prove robust to the Great Moderation.

\section{Conclusion}

This paper investigates the properties of the variance in quarterly real GDP growth rates and their effects on conditional volatility for Canada, Japan, the U.K., and the U.S. during the period 1957:1 to $2006: 3$ as well as the effects, if any, of output growth volatility on output growth . We begin by considering the possible effects, if any, of structural change on the volatility process. Our initial results, based on a GARCH model of the conditional variance of the residuals, find strong evidence of volatility persistence and excess kurtosis in the growth rate. Subsequent analysis reveals that this conclusion does not prove robust to a one-time shift in output volatility, identified by the modified ICSS algorithm. First, the findings of a high volatility persistence measured by the GARCH model disappear in the specifications that include a dummy variable for the structural break. That is, the IGARCH effect proves spurious. Second, excess kurtosis vanishes or drops substantially in the specifications that include the dummy variable in the GARCH process. These results demonstrate the misspecification of GARCH models, if researchers neglect the nonstationary unconditional variance. 
We can resolve the two puzzles of high conditional volatility persistence and excess kurtosis completely when we introduce dummy variables for the Great Moderation in the GARCH models for Canada, Japan, and the U.S. The excess kurtosis, however, remains unresolved for the U.K. That is, although it drops substantially, leptokurtosis in the unconditional distribution of output growth rates remains after adjustment for GARCH with conditional normality. Speight (1999) and Ho and Tsui (2003) face the same issue in their studies of the U.K. Baillie and Bollerslev (1989) show that although the use of the conditional normal distribution can generate a leptokurtic unconditional distribution (for the exchange rate), it cannot adequately capture the degree of kurtosis in the unconditional distribution. The t-distribution possesses more power in explaining leptokurtosis (for the exchange rate) than the normal distribution. We experimented with the $\operatorname{GARCH}(1,1)$ model with a t-distribution and the structural break. Excess kurtosis still appears in the standardized residuals. An explanation for this excess kurtosis remains a topic worthy of future research. 


\section{References}

Aggarwal, R., Inclán, C. and Leal, R. (1999) Volatility in emerging stock markets, Journal of Financial and Quantitative Analysis 34, 33-55.

Ahmed, S., Levin, A. and Wilson, B.A. (2004) Recent U.S. macroeconomic stability: Good policies, good practices, or good luck? Review of Economics and Statistics 86, 824-832.

Baillie, R. T. and Bollerslev, T. (1989) The message in daily exchange rates: a conditional-variance tale, Journal of Business and Economic Statistics 7, 297-305.

Bernanke, B.S. (2004) The Great Moderation, speech at Eastern Economic Association, Washington, February 20.

Berndt, E. K., Hall, B. H., Hall, R. E. and Hausmann, J. A. (1974) Estimation and inference in nonlinear structural models, Annals of Economic and Social Measurement 4, 653-665.

Bhar, R. and Hamori, S. (2003) Alternative characterization of the volatility in the growth rate of real GDP, Japan and the World Economy 15, 223-231.

Black, F. (1987) Business Cycles and Equilibrium, Basil Blackwell, New York.

Blackburn, K. (1999) Can stabilization policy reduce long-run growth? Economic Journal 109, $67-77$

Blanchard, O. and Simon, J. (2001) The long and large decline in U.S. output volatility, Brookings Papers on Economic Activity 32, 135-174.

Bollerslev, T. and Wooldridge, J. M. (1992) Quasi-maximum likelihood estimation and inference in dynamic models with time varying covariance, Econometric Reviews 11, 143-172.

Caporale, T. and McKiernan, B. (1996) The relationship between output variability and growth: Evidence from post war UK data, Scottish Journal of Political Economy 43, 229-236. 
Caporale, T. and McKiernan, B. (1998) The Fischer Black hypothesis: Some time-series evidence, Southern Economic Journal 63, 765-771.

Diebold, F. (1986) Comments on modelling the persistence of conditional variance, Econometric Reviews 5, 51-56.

Eggers, A. and Ioannides, Y. M. (2006) The role of output composition in the stabilization of US output growth, Journal of Macroeconomics 28, 585-595.

Engle, R. F. and Bollerslev, T. (1986) Modelling the persistence of conditional variance, Econometric Reviews 5, 1-50.

Engle, R. F., Lilien, D. and Robins, R. (1987) Estimating time varying risk premia in the term structure: The ARCH-M model, Econometrica 55, 391-407.

Engle, R. F. and Ng, V. (1993) Measuring and testing the impact of news on volatility, Journal of Finance 48, 1749-1778.

Fountas, S. and Karanasos, M. (2006) The relationship between economic growth and real uncertainty in the G3, Economic Modelling 23, 638-647.

Fountas, S., Karanasos, M., and Mendoza, A. (2004) Output variability and economic growth: the Japanese case, Bulletin of Economic Research 56, 353-363.

Friedman, M. (1968) The role of monetary policy, American Economic Review 58, 1-17.

Glosten, L., Jagannathan, R. and Runkle, D. (1993) On the relation between the expected value and the volatility of the nominal excess return on stocks, Journal of Finance 48, 1779-1801.

Grier, K. B. and Perry, M. J. (2000) The effects of real and nominal uncertainty on inflation and output growth: Some GARCH-M evidence, Journal of Applied Econometrics 15, 45-58. 
Hamilton, J. D. and Susmel, R. (1994) Autoregressive conditional heteroskedasticity and changes in regime, Journal of Econometrics 64, 307-333.

Hamori, S. (2000) Volatility of real GDP: Some evidence from the United States, the United Kingdom and Japan, Japan and the World Economy 12, 143-152.

Henry, O. T. and Olekalns, N. (2002) The effect of recessions on the relationship between output variability and growth, Southern Economic Journal 68, 683-692.

Hillebrand, E. (2005) Neglecting parameter changes in GARCH models, Journal of Econometrics $129,121-138$.

Ho, K. Y. and Tsui, A. K. C. (2003) Asymmetric volatility of real GDP: Some evidence from Canada, Japan, the United Kingdom and the United States, Japan and the World Economy $15,437-445$.

Inclán, C. and Tiao, G. C. (1994) Use of cumulative sums of squares for retrospective detection of changes of variance, Journal of the American Statistical Association, 89, 913-923.

Kim, C. J. and Nelson, C. R. (1999) Has the U.S. economy become more stable? A Bayesian approach based on a Markov-Switching model of the business cycle, Review of Economics and Statistics 81, 1-10.

Kim, C. J., Nelson, C. R. and Startz, R. (1998) Testing for mean reversion in heteroskedastic data based on Gibbs sampling augmented randomization, Journal of Empirical Finance 5, $131-154$

Lamoureux, C. G. and Lastrapes, W. D. (1990) Persistence in variance, structural change and the GARCH model, Journal of Business and Economic Statistics 8, 225-234.

Lastrapes, W. D. (1989) Exchange rate volatility and U.S. monetary policy: An ARCH application, Journal of Money, Credit, and Banking 21, 66-77. 
Lucas, R. E. (1972) Expectations and the neutrality of money, Journal of Economic Theory 4, 103-124.

Martin, P. and Rogers, C.A. (1997) Stabilization policy, learning by doing, and economic growth, Oxford Economic Papers 49, 152-166.

Martin, P. and Rogers, C.A. (2000) Long-term growth and short-term economic instability, European Economic Review 44, 359-381.

McConnell, M. M. and Perez-Quiros, G. (2000) Output fluctuations in the United States: What has changed since the early 1980's? American Economic Review 90, 1464-1476.

Mikosch, T. and Stărică, C. (2004) Non-stationarities in financial time series, the long-range dependence, and the IGARCH effects, Review of Economics and Statistics 86, 378-390.

Mills, T. C. and Wang, P. (2003) Have output growth rates stabilized? Evidence from the G-7 economies, Scottish Journal of Political Economy 50, 232-246.

Newey, W. K. and West, K. D. (1994) Automatic lag selection in covariance matrix estimation, Review of Economic Studies 61, 631-654.

Phelps, E. S. (1968) Money wage dynamics and labor market equilibrium, Journal of Political Economy 76, 678-711.

Poterba, J. M. and Summers L. H. (1986) The persistence of volatility and stock market fluctuations, American Economic Review 76, 1142-1151.

Rapach, D. E. and Strauss, J. K. (2007) Structural breaks and GARCH models of exchange rate volatility, Journal of Applied Econometrics , forthcoming.

Sansó, A., Arragó, V. and Carrion, J. L. (2004) Testing for change in the unconditional variance of financial time series, Revista de Economiá Financiera 4, 32-53. 
Sensier, M. and van Dijk, D. (2004) Testing for volatility changes in U.S. macroeconomic time series, Review of Economics and Statistics 86, 833-839.

Speight, A. E. H. (1999) UK output variability and growth: Some further evidence, Scottish Journal of Political Economy 46, 175-184.

Stock, J. H. and Watson, M. W. (2003) Has the business cycle changed? Evidence and explanations, Monetary Policy and Uncertainty: Adapting to a Changing Economy, proceedings of symposium sponsored by Federal Reserve Bank of Kansas City, Jackson Hole, Wyo., 9-56.

Summers, P. M. (2005) What caused the Great Moderation? Some cross-country evidence, Economic Review (Third Quarter), Federal Reserve Bank of Kansas City, 5-32.

Tzavalis, E. and Wickens, M. R. (1995) The persistence in volatility of the US term premium 1970-1986, Economics Letters 49, 381-389. 
Table 1: $\quad$ Descriptive Statistics for Quarterly Real GDP Growth

Panel A: $\quad$ Moments of Full-Sample and ADF Test

\begin{tabular}{lcccc}
\hline & Canada & Japan & United Kingdom & United States \\
\hline Mean & 0.8589 & 1.0941 & 0.6107 & 0.8103 \\
Standard deviation & 0.8854 & 1.7906 & 0.9947 & 0.9048 \\
Skewness & -0.0182 & $0.3602^{*}$ & $0.3248^{* *}$ & $-0.3978^{*}$ \\
& {$[0.9173]$} & {$[0.0399]$} & {$[0.0640]$} & {$[0.0233]$} \\
Excess kurtosis & 0.4725 & $2.1619^{*}$ & $3.7528^{*}$ & $1.6566^{*}$ \\
& {$[0.1824]$} & {$[0.0000]$} & {$[0.0000]$} & {$[0.0000]$} \\
Jacque-Bera normality test & 1.8529 & $42.8432^{*}$ & $119.6738^{*}$ & $27.8644^{*}$ \\
& {$[0.3959]$} & {$[0.0000]$} & {$[0.0000]$} & {$[0.0000]$} \\
ADF(n) & $-11.0336(0)^{*}$ & $-3.2665(3)^{*}$ & $-14.8952(0)^{*}$ & $-10.3983(0)^{*}$ \\
\hline
\end{tabular}

Panel B: $\quad$ Break Date and Mean and Standard Deviation of Sub-Sample

\begin{tabular}{lccccc}
\hline & Break date & Period & Mean & $\begin{array}{c}\text { Standard } \\
\text { deviation }\end{array}$ & 3-Standard deviation \\
\hline Canada & $1991: 2$ & $1957: 1-1991: 1$ & 0.9056 & 1.0171 & $2.4312,-1.5256$ \\
& & $1991: 2-2006: 3$ & 0.7566 & 0.4762 & $1.4709,-0.7143$ \\
Japan & $1975: 1$ & $1957: 1-1974: 4$ & 2.2866 & 1.9587 & $5.2246,-0.6514$ \\
& & $1975: 1-2006: 3$ & 0.4977 & 1.1351 & $2.2003,-1.2049$ \\
United Kingdom & \multirow{2}{*}{$1991: 4$} & $1957: 1-1991: 3$ & 0.5811 & 1.1743 & $2.3425,-1.7614$ \\
& & $1991: 4-2006: 3$ & 0.6789 & 0.3079 & $1.1407,-0.4618$ \\
United States & \multirow{2}{*}{$1982: 1$} & $1957: 1-1981: 4$ & 0.8361 & 1.1297 & $2.5306,-1.6945$ \\
& & $1982: 1-2006: 3$ & 0.7844 & 0.6069 & $1.6947,-0.9103$ \\
\hline
\end{tabular}

Panel B1: $\quad$ Structural Stability Test for the Unconditional Mean

\begin{tabular}{lcccc}
\hline & Canada & Japan & United Kingdom & United States \\
\hline Full sample v.s. Sub-sample 1 & -0.4337 & $-4.3712^{*}$ & 0.2422 & -0.1977 \\
& {$[0.6648]$} & {$[0.0000]$} & {$[0.8087]$} & {$[0.8434]$} \\
Full sample v.s. Sub-sample 2 & 1.1722 & $4.0245^{*}$ & -0.8411 & 0.2911 \\
& {$[0.2425]$} & {$[0.0000]$} & {$[0.4010]$} & {$[0.7711]$} \\
Sub-sample 1 v.s. Sub-sample 2 & 1.4034 & $7.0193 *$ & -0.9098 & 0.4004 \\
& {$[0.1620]$} & {$[0.0000]$} & {$[0.3641]$} & {$[0.6893]$} \\
\hline
\end{tabular}

Panel B2: $\quad$ Structural Stability Test for the Unconditional Variance

\begin{tabular}{lcccc}
\hline Full sample v.s. Sub-sample 1 & $0.7578^{*}$ & $0.7600^{* *}$ & $0.7175^{*}$ & $0.6415^{*}$ \\
& {$[0.0379]$} & {$[0.0743]$} & {$[0.0164]$} & {$[0.0045]$} \\
Full sample v.s. Sub-sample 2 & $3.4561^{*}$ & $2.2628^{*}$ & $10.4325^{*}$ & $2.2225^{*}$ \\
& {$[0.0000]$} & {$[0.0000]$} & {$[0.0000]$} & {$[0.0000]$} \\
Sub-sample 1 v.s. Sub-sample 2 & $4.5607^{*}$ & $2.9773^{*}$ & $14.5400^{*}$ & $3.4641^{*}$ \\
& {$[0.0000]$} & {$[0.0000]$} & {$[0.0000]$} & {$[0.0000]$}
\end{tabular}

Note: P-values appear in brackets; 0.0000 indicates less than 0.00005 . The measures of skewness and kurtosis are normally distributed as $N(0,6 / T)$ and $N(0,24 / T)$, respectively, where $T$ equals the number of observations. ADF $(n)$ equals the augmented Dickey-Fuller unit-root test with lags $n$ selected by the SBC. The Wald test $\left(\hat{\mu}_{i}-\hat{\mu}_{j}\right)^{2} /\left(S D_{i}^{2}+S D_{j}^{2}\right)$ tests for structural change in the unconditional mean between the different regime and is distributed as $\chi^{2}(1) . F$ test equals the unconditional variance ratio test between the samples $i$ and $j$, and is asymptotically distributed as $F\left(d f_{i}, d f_{j}\right)$, where $d f$ denotes the degrees of freedom.

* denotes 5-percent significance level.

** denotes 10-percent significance level. 
Table 2: $\quad$ AR-GARCH(1,1) Estimates without a Structural Break

\begin{tabular}{|c|c|c|c|c|}
\hline Coefficient & Canada & Japan & United Kingdom & United States \\
\hline$a_{0}$ & $\begin{array}{c}0.5326^{*} \\
(0.0761)\end{array}$ & $\begin{array}{c}0.1713 \\
(0.1129)\end{array}$ & $\begin{array}{l}0.6032 * \\
(0.1297)\end{array}$ & $\begin{array}{l}0.4870^{*} \\
(0.0901)\end{array}$ \\
\hline$a_{1}$ & $\begin{array}{l}0.3224^{*} \\
(0.0802)\end{array}$ & $\begin{array}{l}-0.0775 \\
(0.0819)\end{array}$ & $\begin{array}{c}-0.1095 \\
(0.1071)\end{array}$ & $\begin{array}{l}0.2135^{*} \\
(0.0742)\end{array}$ \\
\hline$a_{2}$ & & $\begin{array}{l}0.2800^{*} \\
(0.0760)\end{array}$ & $\begin{array}{c}0.0160 \\
(0.1091)\end{array}$ & $\begin{array}{l}0.2256^{*} \\
(0.0767)\end{array}$ \\
\hline$a_{3}$ & & $\begin{array}{c}0.2573 * \\
(0.0790)\end{array}$ & $\begin{array}{l}0.2545^{*} \\
(0.1063)\end{array}$ & \\
\hline$a_{4}$ & & $\begin{array}{l}0.2171^{*} \\
(0.0709)\end{array}$ & & \\
\hline$\alpha_{0}$ & $\begin{array}{c}0.0199 \\
(0.0170)\end{array}$ & $\begin{array}{c}0.0539 \\
(0.0624)\end{array}$ & $\begin{array}{c}0.1043 \\
(0.0875)\end{array}$ & $\begin{array}{c}0.0173 \\
(0.0161)\end{array}$ \\
\hline$\alpha_{1}$ & $\begin{array}{l}0.2280^{*} \\
(0.0750)\end{array}$ & $\begin{array}{l}0.1218^{*} \\
(0.0518)\end{array}$ & $\begin{array}{l}0.2576^{*} \\
(0.1254)\end{array}$ & $\begin{array}{l}0.1976^{*} \\
(0.0590)\end{array}$ \\
\hline$\beta_{1}$ & $\begin{array}{l}0.7632 * \\
(0.0620)\end{array}$ & $\begin{array}{l}0.8521^{*} \\
(0.0526)\end{array}$ & $\begin{array}{l}0.7117 * \\
(0.1375)\end{array}$ & $\begin{array}{l}0.7866^{*} \\
(0.0549)\end{array}$ \\
\hline LR & $\begin{array}{c}0.0506 \\
{[0.8222]}\end{array}$ & $\begin{array}{c}0.3124 \\
{[0.5768]}\end{array}$ & $\begin{array}{c}0.1722 \\
{[0.6786]}\end{array}$ & $\begin{array}{c}0.2350 \\
{[0.6278]}\end{array}$ \\
\hline Function value & -232.3200 & -343.8104 & -249.2206 & -226.9939 \\
\hline LB Q (3) & $\begin{array}{c}3.3208 \\
{[0.3447]}\end{array}$ & $\begin{array}{c}0.2244 \\
{[0.9735]}\end{array}$ & $\begin{array}{c}2.2249 \\
{[0.5270]}\end{array}$ & $\begin{array}{c}1.9193 \\
{[0.5893]}\end{array}$ \\
\hline LB Q (6) & $\begin{array}{c}4.2957 \\
{[0.6367]}\end{array}$ & $\begin{array}{c}0.9083 \\
{[0.9888]}\end{array}$ & $\begin{array}{c}5.1998 \\
{[0.5184]}\end{array}$ & $\begin{array}{c}4.5756 \\
{[0.5992]}\end{array}$ \\
\hline $\mathbf{L B} Q^{2}(3)$ & $\begin{array}{c}0.8552 \\
{[0.8362]}\end{array}$ & $\begin{array}{c}0.1528 \\
{[0.9848]}\end{array}$ & $\begin{array}{c}0.9535 \\
{[0.8125]}\end{array}$ & $\begin{array}{c}1.2104 \\
{[0.7505]}\end{array}$ \\
\hline LB $Q^{2}(\mathbf{6})$ & $\begin{array}{c}3.0656 \\
{[0.8005]}\end{array}$ & $\begin{array}{c}1.0524 \\
{[0.9835]}\end{array}$ & $\begin{array}{c}2.2259 \\
{[0.8977]}\end{array}$ & $\begin{array}{c}4.3785 \\
{[0.6255]}\end{array}$ \\
\hline Engle-Ng & $\begin{array}{c}1.5069 \\
{[0.6806]}\end{array}$ & $\begin{array}{c}4.2587 \\
{[0.2348]}\end{array}$ & $\begin{array}{c}2.8096 \\
{[0.4219]}\end{array}$ & $\begin{array}{c}2.0693 \\
{[0.5581]}\end{array}$ \\
\hline Skewness & $\begin{array}{c}-0.1298 \\
{[0.4603]}\end{array}$ & $\begin{array}{c}-0.4094^{*} \\
{[0.0208]}\end{array}$ & $\begin{array}{l}0.5611 * \\
{[0.0015]}\end{array}$ & $\begin{array}{c}0.1058 \\
{[0.5481]}\end{array}$ \\
\hline Excess kurtosis & $\begin{array}{l}1.1503 * \\
{[0.0012]}\end{array}$ & $\begin{array}{l}1.8385^{*} \\
{[0.0000]}\end{array}$ & $\begin{array}{l}3.2265^{*} \\
{[0.0000]}\end{array}$ & $\begin{array}{c}0.9293 * \\
{[0.0090]}\end{array}$ \\
\hline Jacque-Bera & $\begin{array}{l}11.4153^{*} \\
{[0.0033]}\end{array}$ & $\begin{array}{c}32.7438^{*} \\
{[0.0000]}\end{array}$ & $\begin{array}{l}94.8209^{*} \\
{[0.0000]}\end{array}$ & $\begin{array}{c}7.4190^{*} \\
{[0.0244]}\end{array}$ \\
\hline
\end{tabular}

Note: Standard errors appear in parentheses; p-values appear in brackets; $L B Q(k)$ and $L B Q^{2}(k)$ equal Ljung-Box Q-statistics, testing for standardized residuals and squared standardized residuals for autocorrelations up to $k$ lags. LR equals the likelihood ratio statistic, following a $\chi^{2}$ distribution with one degree of freedom that tests for $\alpha_{1}+\beta_{1}=1$. Engle-Ng equals the TR2 statistics, following a $\chi^{2}$ distribution with 3 degrees of freedom that tests for asymmetric volatility.

* denotes 5-percent significance level.

** denotes 10-percent significance level. 
Table 3: $\quad$ AR-GARCH(1,1) Estimates with a Structural Break

$$
\begin{aligned}
& y_{t}=a_{0}+\sum_{i=1}^{4} a_{i} y_{t-i}+\varepsilon_{t} \\
& \sigma_{t}^{2}=\alpha_{0}+\alpha_{1} \varepsilon_{t-1}^{2}+\beta_{1} \sigma_{t-1}^{2}+\gamma \quad \text { Dummy }_{j}, j=C, J, U K, \text { and } U S,
\end{aligned}
$$

where Dummy $_{C}=1$ for $t \geqq 1991: 2 ; 0$ otherwise for Canada, Dummy $=1$ for $t \geqq$ 1975:1; 0 otherwise for Japan, Dummy ${ }_{U K}=1$ for $t \geqq 1$ 1991:4; 0 otherwise for the U.K.,

\begin{tabular}{|c|c|c|c|c|}
\hline Coefficient & Canada & Japan & United Kingdom & United States \\
\hline$a_{0}$ & $\begin{array}{l}0.5235^{*} \\
(0.0772)\end{array}$ & $\begin{array}{l}1.3290^{*} \\
(0.3397)\end{array}$ & $\begin{array}{l}0.5051^{*} \\
(0.0778)\end{array}$ & $\begin{array}{l}0.5435^{*} \\
(0.0716)\end{array}$ \\
\hline$a_{1}$ & $\begin{array}{c}0.3792^{*} \\
(0.0769)\end{array}$ & $\begin{array}{l}-0.0942 \\
(0.0653)\end{array}$ & $\begin{array}{c}0.0006 \\
(0.0770)\end{array}$ & $\begin{array}{l}0.2625^{*} \\
(0.0696)\end{array}$ \\
\hline$a_{2}$ & & $\begin{array}{l}0.1904^{*} \\
(0.0667)\end{array}$ & $\begin{array}{c}0.0521 \\
(0.0776)\end{array}$ & $\begin{array}{c}0.0985 * * \\
(0.0555)\end{array}$ \\
\hline$a_{3}$ & & $\begin{array}{l}0.1300^{*} \\
(0.0652)\end{array}$ & $\begin{array}{l}0.2190^{*} \\
(0.0705)\end{array}$ & \\
\hline$a_{4}$ & & $\begin{array}{l}0.2197^{*} \\
(0.0551)\end{array}$ & & \\
\hline$d_{1}$ & & $\begin{array}{c}-8.8008^{*} \\
(0.2993)\end{array}$ & & \\
\hline$d_{2}$ & & $\begin{array}{c}-1.0621^{*} \\
(0.3209)\end{array}$ & & \\
\hline$\alpha_{0}$ & $\begin{array}{l}0.7949 * \\
(0.0697)\end{array}$ & $\begin{array}{c}2.2450 * * \\
(1.3108)\end{array}$ & $\begin{array}{l}0.6400^{*} \\
(0.2840)\end{array}$ & $\begin{array}{l}1.0165^{*} \\
(0.0734)\end{array}$ \\
\hline$\alpha_{1}$ & $\begin{array}{c}0.2239 * * \\
(0.1331)\end{array}$ & $\begin{array}{l}0.2022 * \\
(0.0995)\end{array}$ & $\begin{array}{l}0.2985^{*} \\
(0.1150)\end{array}$ & $\begin{array}{c}0.0637 \\
(0.0719)\end{array}$ \\
\hline$\beta_{1}$ & $\begin{array}{c}0.0011 \\
(0.1562)\end{array}$ & $\begin{array}{c}0.1815 \\
(0.3899)\end{array}$ & $\begin{array}{c}0.3240 \\
(0.2071)\end{array}$ & $\begin{array}{c}0.1446 \\
(0.1670)\end{array}$ \\
\hline$\gamma$ & $\begin{array}{l}-0.6825^{*} \\
(0.1523)\end{array}$ & $\begin{array}{c}-1.6097^{* *} \\
(0.9732)\end{array}$ & $\begin{array}{l}-0.6129^{*} \\
(0.2738)\end{array}$ & $\begin{array}{c}-0.8624^{*} \\
(0.0847)\end{array}$ \\
\hline LR & $\begin{array}{c}24.8961^{*} \\
{[0.0000]}\end{array}$ & $\begin{array}{c}2.9594 * * \\
{[0.0871]}\end{array}$ & $\begin{array}{l}6.0729^{*} \\
{[0.0146]}\end{array}$ & $\begin{array}{c}38.5980^{*} \\
{[0.0000]}\end{array}$ \\
\hline Function value & -224.1775 & -316.4242 & -218.3995 & -221.5502 \\
\hline LB Q (3) & $\begin{array}{c}3.9460 \\
{[0.2673]}\end{array}$ & $\begin{array}{r}0.1870 \\
{[0.9796]}\end{array}$ & $\begin{array}{c}3.6545 \\
{[0.3012]}\end{array}$ & $\begin{array}{c}3.4161 \\
{[0.3318]}\end{array}$ \\
\hline LB Q (6) & $\begin{array}{c}5.2913 \\
{[0.5070]}\end{array}$ & $\begin{array}{c}1.4023 \\
{[0.9657]}\end{array}$ & $\begin{array}{c}5.1487 \\
{[0.5248]}\end{array}$ & $\begin{array}{c}5.8169 \\
{[0.4440]}\end{array}$ \\
\hline LB $Q^{2}(3)$ & $\begin{array}{c}2.4812 \\
{[0.4786]}\end{array}$ & $\begin{array}{c}0.7378 \\
{[0.8642]}\end{array}$ & $\begin{array}{c}0.1874 \\
{[0.9795]}\end{array}$ & $\begin{array}{c}5.0353 \\
{[0.1692]}\end{array}$ \\
\hline LB $Q^{2}(6)$ & $\begin{array}{c}5.1472 \\
{[0.5250]}\end{array}$ & $\begin{array}{c}2.4769 \\
{[0.8710]}\end{array}$ & $\begin{array}{c}1.9060 \\
{[0.9281]}\end{array}$ & $\begin{array}{c}6.6421 \\
{[0.3552]}\end{array}$ \\
\hline Engle-Ng & $\begin{array}{c}3.0418 \\
{[0.3852]}\end{array}$ & $\begin{array}{l}6.6584 * * \\
{[0.0836]}\end{array}$ & $\begin{array}{c}1.4213 \\
{[0.7005]}\end{array}$ & $\begin{array}{c}1.2655 \\
{[0.7373]}\end{array}$ \\
\hline Skewness & $\begin{array}{c}-0.0413 \\
{[0.8142]}\end{array}$ & $\begin{array}{c}0.0458 \\
{[0.7959]}\end{array}$ & $\begin{array}{c}0.3352 * * \\
{[0.0579]}\end{array}$ & $\begin{array}{c}-0.0508 \\
{[0.7730]}\end{array}$ \\
\hline Excess kurtosis & $\begin{array}{c}0.2696 \\
{[0.4479]}\end{array}$ & $\begin{array}{c}-0.4664 \\
{[0.1927]}\end{array}$ & $\begin{array}{l}1.0127^{*} \\
{[0.0045]}\end{array}$ & $\begin{array}{c}0.0995 \\
{[0.7799]}\end{array}$ \\
\hline Jacque-Bera & $\begin{array}{c}0.6528 \\
{[0.7215]}\end{array}$ & $\begin{array}{c}1.8269 \\
{[0.4011]}\end{array}$ & $\begin{array}{l}11.9853^{*} \\
{[0.0024]}\end{array}$ & $\begin{array}{c}0.1653 \\
{[0.9206]}\end{array}$ \\
\hline
\end{tabular}
and Dummy $_{U S}=1$ for $t \geqq 1982: 1 ; 0$ otherwise for the U.S. 
Table 4: AR-GARCH(1,1)-M Estimates with a Structural Break

$y_{t}=a_{0}+\sum_{i=1}^{4} a_{i} y_{t-i}+\lambda \sigma_{t}+\varepsilon_{t}$

$\sigma_{t}^{2}=\alpha_{0}+\alpha_{1} \varepsilon_{t-1}^{2}+\beta_{1} \sigma_{t-1}^{2}+\gamma$ Dummy $_{j}, j=C, J, U K$, and US,

where Dummy $_{C}=1$ for $t \geqq 1991: 2$; 0 otherwise for Canada, Dummy $=1$ for $t \geqq$ 1975:1; 0 otherwise for Japan, Dummy ${ }_{U K}=1$ for $t \geqq 1991: 4$; 0 otherwise for the U.K., and Dummy $_{U S}=1$ for $t \geqq 1982: 1 ; 0$ otherwise for the U.S.

\begin{tabular}{|c|c|c|c|c|}
\hline Coefficient & Canada & Japan & United Kingdom & United States \\
\hline \multirow[t]{2}{*}{$a_{0}$} & $0.3238^{*}$ & 2.1740 & $0.5195^{*}$ & $0.4772 *$ \\
\hline & $(0.1120)$ & $(1.3968)$ & $(0.0892)$ & $(0.1467)$ \\
\hline \multirow{2}{*}{$a_{1}$} & $0.2941^{*}$ & -0.0966 & 0.0090 & $0.2830 *$ \\
\hline & $(0.0689)$ & $(0.0651)$ & $(0.0770)$ & $(0.0805)$ \\
\hline \multirow{2}{*}{$a_{2}$} & & $0.1957^{*}$ & 0.0606 & $0.1341^{*}$ \\
\hline & & $(0.0666)$ & $(0.0778)$ & $(0.0693)$ \\
\hline \multirow{2}{*}{$a_{3}$} & & $0.1400^{*}$ & $0.1976^{*}$ & \\
\hline & & $(0.0657)$ & $(0.0706)$ & \\
\hline \multirow{2}{*}{$a_{4}$} & & $0.2125^{*}$ & & \\
\hline & & $(0.0551)$ & & \\
\hline \multirow{2}{*}{$d_{1}$} & & $-5.8500^{*}$ & & \\
\hline & & $(2.7032)$ & & \\
\hline \multirow{2}{*}{$d_{2}$} & & $-1.4170 *$ & & \\
\hline & & $(0.6627)$ & & \\
\hline \multirow[t]{2}{*}{$\lambda$} & $0.3693 *$ & -0.4822 & -0.0332 & 0.0344 \\
\hline & $(0.1675)$ & $(0.7396)$ & $(0.1130)$ & $(0.1933)$ \\
\hline \multirow{2}{*}{$\alpha_{0}$} & $0.6058^{*}$ & $2.9232 *$ & $0.6117^{*}$ & $0.9174 *$ \\
\hline & $(0.2677)$ & $(1.2390)$ & $(0.2764)$ & $(0.1006)$ \\
\hline \multirow{2}{*}{$\alpha_{1}$} & $0.1710^{*}$ & $0.1921^{*}$ & $0.2933^{*}$ & 0.1042 \\
\hline & $(0.0835)$ & $(0.0894)$ & $(0.1137)$ & $(0.0975)$ \\
\hline \multirow{2}{*}{$\beta_{1}$} & 0.2881 & 0.0064 & $0.3511 * *$ & 0.2208 \\
\hline & $(0.2451)$ & $(0.3461)$ & $(0.1995)$ & $(0.1705)$ \\
\hline \multirow[t]{2}{*}{$\gamma$} & $-0.5160 *$ & $-1.9653^{*}$ & $-0.5835^{*}$ & $-0.7644 *$ \\
\hline & $(0.2310)$ & $(0.9091)$ & $(0.2659)$ & $(0.1716)$ \\
\hline \multirow[t]{2}{*}{ LR } & $5.8827 *$ & $5.7332 *$ & $6.0324^{*}$ & 22.26248 \\
\hline & {$[0.0162]$} & {$[0.0177]$} & {$[0.0150]$} & {$[0.0000]$} \\
\hline Function value & -223.7299 & -318.0792 & -217.9148 & -218.8595 \\
\hline \multirow[t]{2}{*}{ LB Q (3) } & 5.5696 & 0.3909 & 2.5099 & 1.8114 \\
\hline & {$[0.1345]$} & [0.9421] & {$[0.4735]$} & {$[0.6124]$} \\
\hline \multirow[t]{2}{*}{ LB Q (6) } & 6.6017 & 0.9946 & 3.9378 & 3.9244 \\
\hline & [0.3592] & [0.9858] & {$[0.6850]$} & [0.6869] \\
\hline \multirow[t]{2}{*}{$\mathbf{L B} Q^{2}(3)$} & 2.2521 & 0.5589 & 0.1446 & 1.9878 \\
\hline & {$[0.5217]$} & [0.9057] & [0.9859] & [0.5749] \\
\hline \multirow[t]{2}{*}{ LB $Q^{2}(6)$} & 7.2100 & 2.3691 & 1.7918 & 2.9654 \\
\hline & {$[0.3018]$} & [0.8828] & {$[0.9378]$} & [0.8131] \\
\hline \multirow[t]{2}{*}{ Engle-Ng } & 1.3150 & 5.9129 & 0.8941 & 0.2865 \\
\hline & {$[0.7255]$} & [0.1159] & {$[0.8268]$} & {$[0.9625]$} \\
\hline \multirow[t]{2}{*}{ Skewness } & -0.0843 & 0.0744 & $0.3664^{*}$ & 0.0108 \\
\hline & {$[0.6315]$} & {$[0.6746]$} & {$[0.0381]$} & {$[0.9510]$} \\
\hline \multirow[t]{2}{*}{ Excess kurtosis } & 0.0806 & -0.4796 & $1.1413^{*}$ & 0.0509 \\
\hline & {$[0.8204]$} & [ 0.1804$]$ & [0.0013] & [0.8863] \\
\hline \multirow[t]{2}{*}{ Jacque-Bera } & 0.2868 & 2.0387 & $14.9500^{*}$ & 0.0249 \\
\hline & [0.8663] & {$[0.3608]$} & {$[0.0005]$} & [0.9875] \\
\hline Note: & & & & \\
\hline
\end{tabular}




\section{Appendix A:}

Table A1: AR-GARCH(1,1) Estimates for Japan

\begin{tabular}{|c|c|c|c|}
\hline Coefficient & With Impulse Dummy & $\begin{array}{c}\text { With Intercept-Shift } \\
\text { Dummy }\end{array}$ & $\begin{array}{c}\text { With Impulse and } \\
\text { Intercept-Shift } \\
\text { Dummy }\end{array}$ \\
\hline$a_{0}$ & $\begin{array}{l}0.2155^{*} \\
(0.1086)\end{array}$ & $\begin{array}{l}1.5970^{*} \\
(0.3407)\end{array}$ & $\begin{array}{l}1.2192 * \\
(0.3445)\end{array}$ \\
\hline$a_{1}$ & $\begin{array}{l}-0.0392 \\
(0.0709)\end{array}$ & $\begin{array}{c}-0.1616^{* *} \\
(0.0911)\end{array}$ & $\begin{array}{l}-0.1014 \\
(0.0696)\end{array}$ \\
\hline$a_{2}$ & $\begin{array}{l}0.2684 * \\
(0.0687)\end{array}$ & $\begin{array}{l}0.2279^{*} \\
(0.0858)\end{array}$ & $\begin{array}{l}0.1818^{*} \\
(0.0683)\end{array}$ \\
\hline$a_{3}$ & $\begin{array}{l}0.2242 * \\
(0.0606)\end{array}$ & $\begin{array}{l}0.1861 * \\
(0.0894)\end{array}$ & $\begin{array}{l}0.1478 * \\
(0.0767)\end{array}$ \\
\hline$a_{4}$ & $\begin{array}{l}0.2925^{*} \\
(0.0540)\end{array}$ & $\begin{array}{l}0.1590^{*} \\
(0.0627)\end{array}$ & $\begin{array}{l}0.2341^{*} \\
(0.0562)\end{array}$ \\
\hline$d_{1}$ & $\begin{array}{l}-8.1176^{*} \\
(0.2133)\end{array}$ & & $\begin{array}{l}-8.7494^{*} \\
(0.3174)\end{array}$ \\
\hline$d_{2}$ & & $\begin{array}{l}-1.3521 * \\
(0.3117)\end{array}$ & $\begin{array}{l}-0.9997 * \\
(0.3158)\end{array}$ \\
\hline$\alpha_{0}$ & $\begin{array}{c}0.0385 \\
(0.0606)\end{array}$ & $\begin{array}{c}0.2048 * * \\
(0.1217)\end{array}$ & $\begin{array}{c}0.0278 \\
(0.0434)\end{array}$ \\
\hline$\alpha_{1}$ & $\begin{array}{l}0.1251 * \\
(0.0720)\end{array}$ & $\begin{array}{l}0.3892 * \\
(0.1139)\end{array}$ & $\begin{array}{l}0.1008 * * \\
(0.0612)\end{array}$ \\
\hline$\beta_{1}$ & $\begin{array}{l}0.8540 * \\
(0.0795)\end{array}$ & $\begin{array}{l}0.5792 * \\
(0.0821)\end{array}$ & $\begin{array}{l}0.8778 * \\
(0.0720)\end{array}$ \\
\hline LR & $\begin{array}{c}0.3141 \\
{[0.5758]}\end{array}$ & $\begin{array}{c}0.0758 \\
{[0.7833]}\end{array}$ & $\begin{array}{c}0.5684 \\
{[0.4518]}\end{array}$ \\
\hline Function value & -328.7155 & -339.0820 & -322.0043 \\
\hline LB Q (3) & $\begin{array}{c}0.3717 \\
{[0.9460]}\end{array}$ & $\begin{array}{c}1.0963 \\
{[0.7779]}\end{array}$ & $\begin{array}{c}0.2365 \\
{[0.9714]}\end{array}$ \\
\hline LB Q (6) & $\begin{array}{r}1.1780 \\
{[0.9779]}\end{array}$ & $\begin{array}{c}1.8101 \\
{[0.9363]}\end{array}$ & $\begin{array}{c}0.7114 \\
{[0.9942]}\end{array}$ \\
\hline LB $Q^{2}(3)$ & $\begin{array}{c}3.1665 \\
{[0.3666]}\end{array}$ & $\begin{array}{r}1.7593 \\
{[0.6238]}\end{array}$ & $\begin{array}{c}4.3282 \\
{[0.2281]}\end{array}$ \\
\hline LB $Q^{2}(\mathbf{6})$ & $\begin{array}{c}6.4751 \\
{[0.3721]}\end{array}$ & $\begin{array}{r}3.4042 \\
{[0.7566]}\end{array}$ & $\begin{array}{c}9.9710 \\
{[0.1258]}\end{array}$ \\
\hline Engle-Ng & $\begin{array}{l}9.7271 * \\
{[0.0210]}\end{array}$ & $\begin{array}{c}0.6721 \\
{[0.8797]}\end{array}$ & $\begin{array}{l}6.6928 * * \\
{[0.0823]}\end{array}$ \\
\hline Skewness & $\begin{array}{c}0.0372 \\
{[0.8335]}\end{array}$ & $\begin{array}{l}-0.4138^{*} \\
{[0.0195]}\end{array}$ & $\begin{array}{c}0.0369 \\
{[0.8348]}\end{array}$ \\
\hline Excess kurtosis & $\begin{array}{c}-0.1349 \\
{[0.7062]}\end{array}$ & $\begin{array}{l}1.52859 * \\
{[0.0000]}\end{array}$ & $\begin{array}{c}-0.3024 \\
{[0.3984]}\end{array}$ \\
\hline Jacque-Bera & $\begin{array}{c}0.1921 \\
{[0.9083]}\end{array}$ & $\begin{array}{c}24.4249 * \\
{[0.0000]}\end{array}$ & $\begin{array}{c}0.7834 \\
{[0.6758]}\end{array}$ \\
\hline $\begin{array}{l}\text { Note: } \\
* \\
* *\end{array}$ & $\begin{array}{l}\text { percent significance level. } \\
\text { percent significance level. }\end{array}$ & & \\
\hline
\end{tabular}


Table A2: AR-EGARCH(1,1) Estimates for Japan

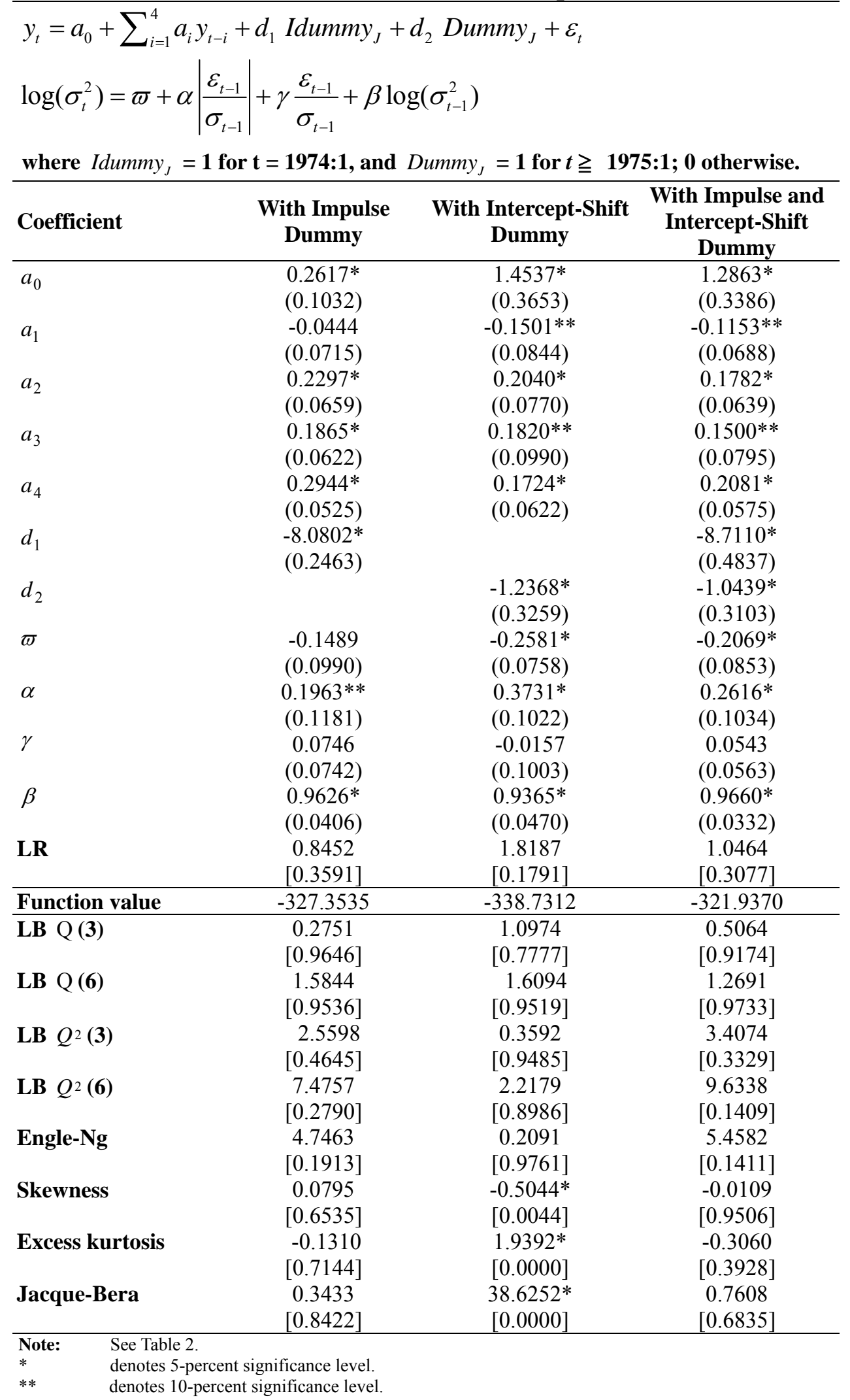




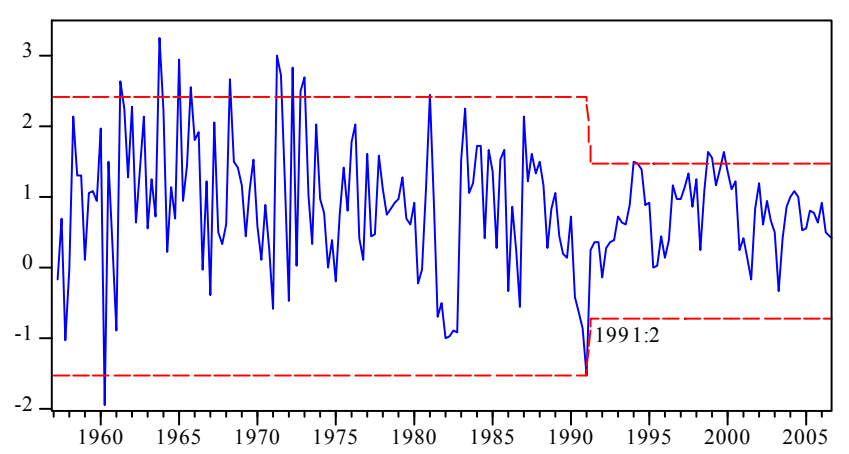

Canada

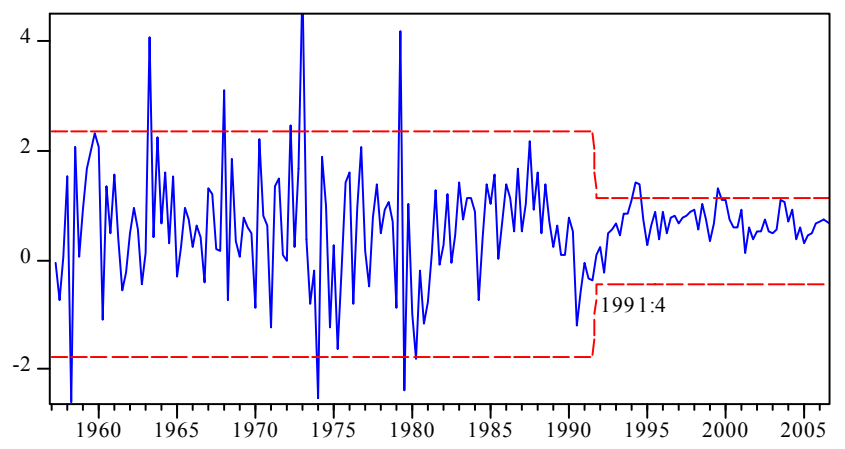

United Kingdom

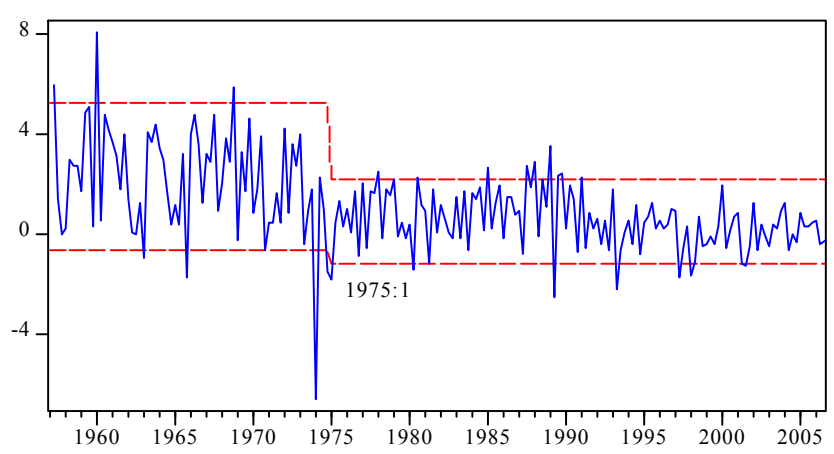

Japan

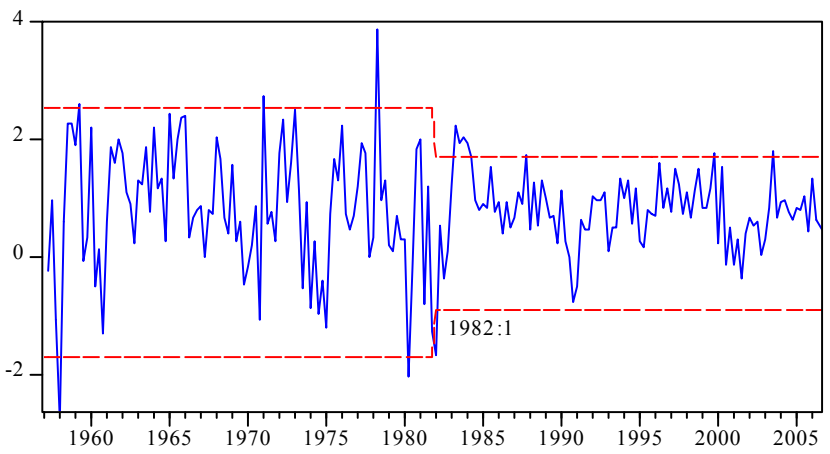

United States

Figure 1. Real GDP Growth Rate 


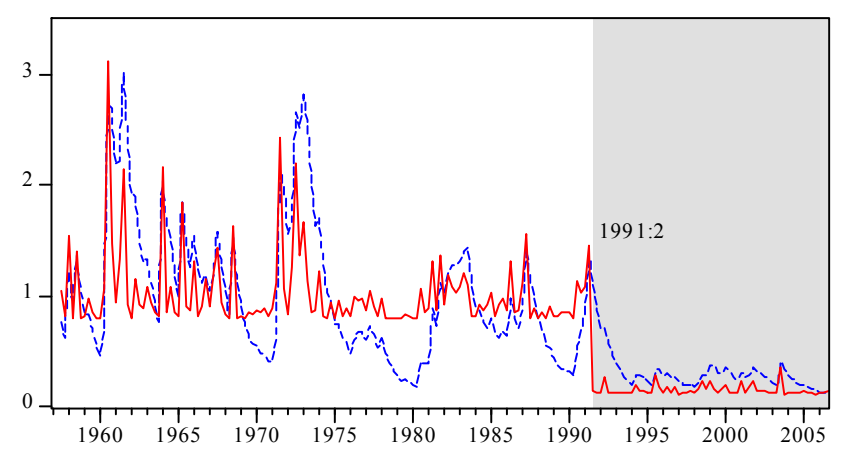

Canada

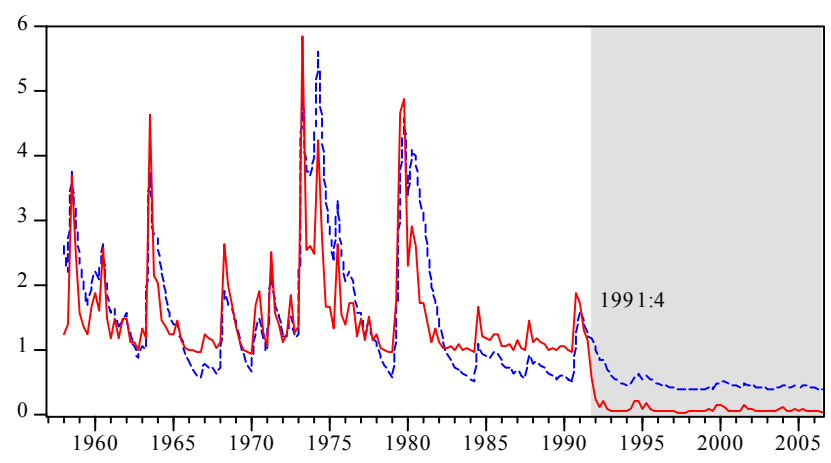

United Kingdom

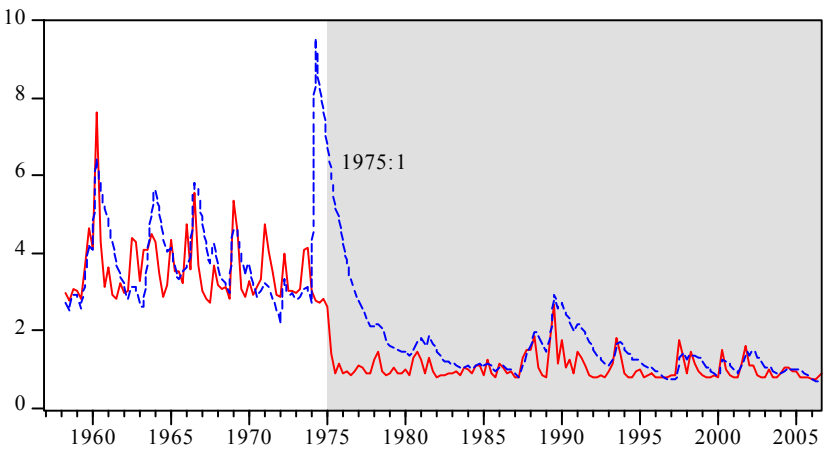

Japan

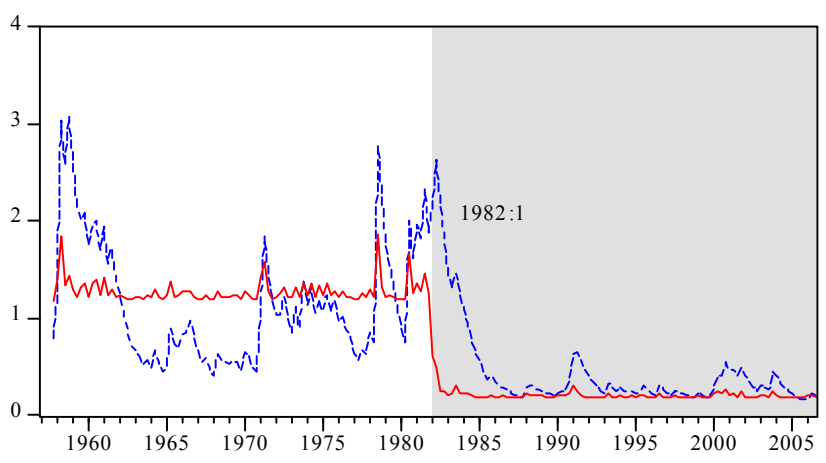

United States

Figure 2. GARCH Variance with (Solid line) and without (Dashed Line) Dummy 